\title{
Autoimmunity and the Oral Cavity
}

\author{
Robert JR Reilly ${ }^{1,2}$ - William Johnston ${ }^{1}$ - Shauna Culshaw ${ }^{1,2}$
}

Published online: 2 February 2019

(C) The Author(s) 2019

\begin{abstract}
Purpose of Review This review aims to make the oral health practitioner and researcher aware of autoimmune diseases that present in the mouth and have implications for oral health. Specifically, the autoimmune pathophysiology, examples of treatments, sequelae, and impact on oral health will be discussed. The limitations of our current knowledge and understanding of these diseases will also be highlighted.

Recent Findings Over the past decade, it has become clear that there is a bidirectional relationship between oral health and autoimmune disease at other body sites; including diabetes and rheumatoid arthritis. Improving the oral health of patients with autoimmune diseases may reduce morbidity associated with such diseases.

Summary Autoimmune diseases impact the oral cavity both directly and indirectly and are increasing in prevalence. As such, there is a growing need for the oral health practitioners to be aware of how autoimmune disease impacts the oral cavity. Further research is necessary to improve our understanding of the bidirectional relationship between oral health and autoimmune disease.
\end{abstract}

Keywords Oral health $\cdot$ Oral disease $\cdot$ Autoimmune disease

\section{Introduction}

Autoimmune diseases (ADs) impact oral health, both directly and indirectly $[1 \bullet \cdot$. This review will discuss ADs that present in the oral cavity as well as ADs affecting other body sites that impact on oral health. It is important for dental and medical practitioners to understand the relationships and challenges ADs present to oral health, and the bidirectional impacts between $\mathrm{AD}$ and oral health.

ADs are defined by their aetiology; the targeting of self antigens by the host immune system [2]. Auto-antigens are targeted by self-reactive $T$ cells or antibodies directed against self, termed auto-antibodies [3]. The auto-antigens' targets include host cells, tissue, or commensal microbiota. Self-reactive lymphocytes are ubiquitously generated; however, these are usually eliminated or

This article is part of the Topical Collection on Systemic Diseases

Shauna Culshaw

Shauna.culshaw@glasgow.ac.uk

1 Oral Sciences, School of Medicine, Dentistry and Nursing, University of Glasgow Dental School, 378 Sauchiehall Street, Glasgow G2 3JZ, UK

2 Institute of Infection, Immunity and Inflammation, College of Medicine, Veterinary and Life Sciences, University of Glasgow, Glasgow, UK regulated before they can elicit their effects. There are multiple mechanisms that regulate this process, collectively known as tolerance. However, breach of tolerance occurs if this system becomes dysregulated and this can result in autoimmune disease $[3,4]$. The dysregulation in autoimmunity is thought to be multifactorial, arising from genetic and environmental factors. ADs can be initiated following infection and this has raised the theory of molecular mimicry; the antigens expressed by an infective pathogen resemble those of the host, resulting in crossreactivity and potentially autoimmune disease $[5,6]$ (Fig. 1). ADs incidence has increased over the last decade and new therapeutics both improve and prolong the life of patients with such disease. This means that oral health professionals will encounter more patients with these diseases [7, 8]. Having the knowledge about ADs and their oral manifestations is essential in delivering quality care to patients with these debilitating diseases. In the following sections, specific examples of $\mathrm{AD}$ are discussed, with particular reference to their relationship with the oral cavity.

\section{Rheumatoid Arthritis}

Rheumatoid arthritis (RA) is a chronic autoimmune disease characterised by progressive joint destruction and pain and swelling of joints. RA affects $1 \%$ of the UK population [9]. 


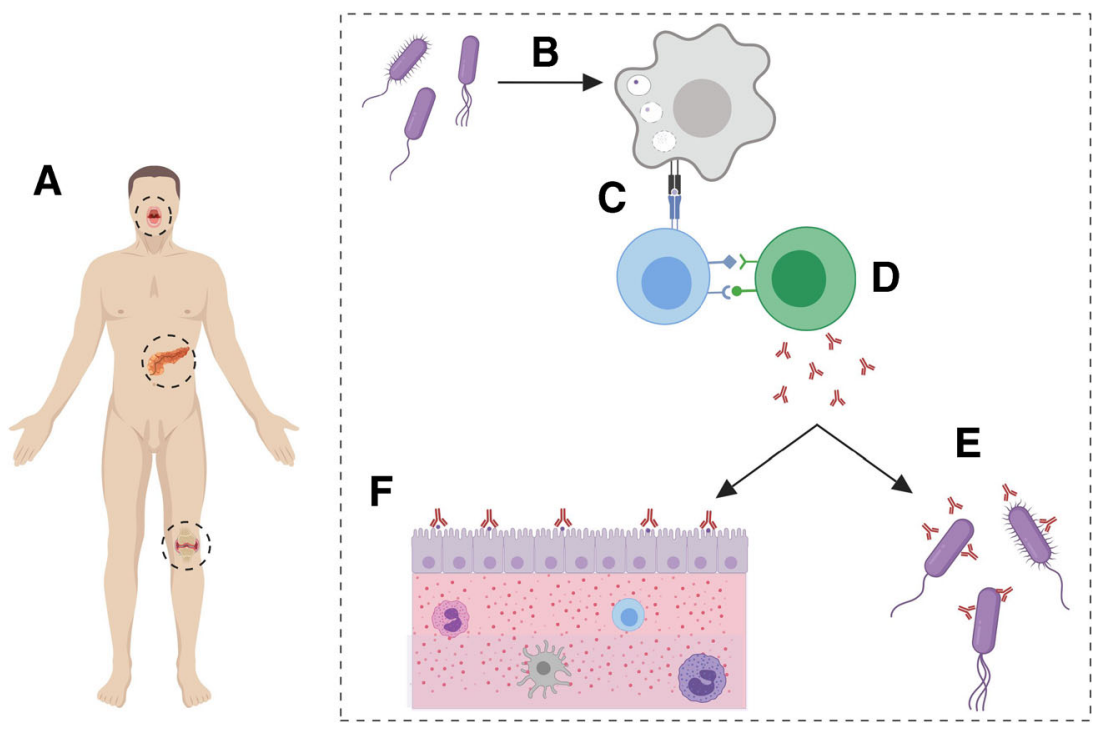

Fig. 1 Model for the microbial induction of autoimmune disease via molecular mimicry - a mechanism of autoimmunity proposed in rheumatoid arthritis, diabetes mellitus, lichen planus, and pemphigoid (A). Following microbial infection, potentially at a site distant to the target of the autoimmune response, certain antigenic determinants of bacteria and viruses are engulfed and processed by antigen presenting cells (APCs) (B). Following processing, the peptide is presented by the APCs to antigen-specific naïve $T$ cells, via the major histocompatibility complex II (MHC II), triggering T cell activation (C). Once activated, T cells provide co-stimulatory signals to B cells, triggering activation and production of antigen-specific antibodies (D). Whilst these antibodies recognise and bind to bacterial antigens $(\mathbf{E})$, they also recognise and bind to self-peptides displayed on specific tissue sites (F). Molecular mimicry of microbial antigens with self-peptides may potentially also result in the activation of autoreactive $\mathrm{T}$ cells and cytokine production, leading to inflammation and tissue damage. Image created with BioRender
The exact aetiology of the disease is not fully understood; however, both genetic and environmental factors play a key role in RA pathogenesis. One potential trigger of RA is microbial dysbiosis and its interaction with the human host, and the periodontium is a site that has been implicated as a trigger for RA [10] (Fig. 2A).

Auto-antibodies against citrullinated peptides (ACPAs) are present in $50-70 \%$ of patients $[11,12]$ and are associated with more severe disease. The auto-antibodies form immune complexes leading to complement activation, perpetuating inflammation and pathology. However, RA is heterogeneous; there are patients, described as 'sero-negative', who do not present with identifiable auto-antibodies $[11,13]$. The extent to which this broad spectrum of disease presentation represents differing disease aetiologies is unconfirmed.

Periodontal disease is more prevalent in patients with rheumatoid arthritis and $80-85 \%$ of patients with RA suffer from periodontitis, compared with $40 \%$ of non-RA control patients [14••]. Patients with RA also demonstrate more alveolar bone loss compared to non-RA controls [15]. Specifically, it has been suggested that Porphyromonas gingivalis, a key pathogen in the aetiology of periodontal disease (PD), plays a role in the development of RA [16]. In a mouse model or RA, when periodontal disease is concurrently induced with $P$. gingivalis, there is an exacerbation of synovitis, compared to controls
[17•]. Intriguingly, patients with RA show an elevated antibody response to $P$. gingivalis virulence factors [18•].

Inflammatory mediators such as interleukin 1 beta (IL-1 $\beta$ ) and tumour necrosis factor alpha (TNF- $\alpha$ ) have been shown to be important in RA and PD pathogenesis [19, 20], and step changes in understanding of RA pathogenesis have led to cytokine and immune cell inhibition strategies for RA treatment. There is a well-documented clinical benefit to anti-TNF- $\alpha$ treatments for RA patients. Further to this research has shown that patients with RA and PD receiving anti-TNF- $\alpha$ treatment have diminished PD. Moreover, it has been suggested that some of these cytokine targeting therapies may be less effective in patients who have uncontrolled PD. There is suggestion that anti$\mathrm{TNF}-\alpha$ and potentially other anti-pro-inflammatory cytokine therapeutics may be beneficial in the treatment of PD. [21]

Importantly RA is also associated with Sjögren's Syndrome $(\mathrm{SjS})$, which is discussed later in this review. RA mainly effects the joints of the hands and legs; however, temporomandibular joints can also be affected [22]. The prevalence of temporomandibular joint dysfunction (TMD) is between 6 and $12 \%$ of the general population. A recent study of TMD in RA patients have shown around $90 \%$ of patients with RA have concurrent TMJ symptoms [23, 24]. Patients with RA and TMD show more evidence of synovitis within the TMJ when examined via MRI scanning [22]. 


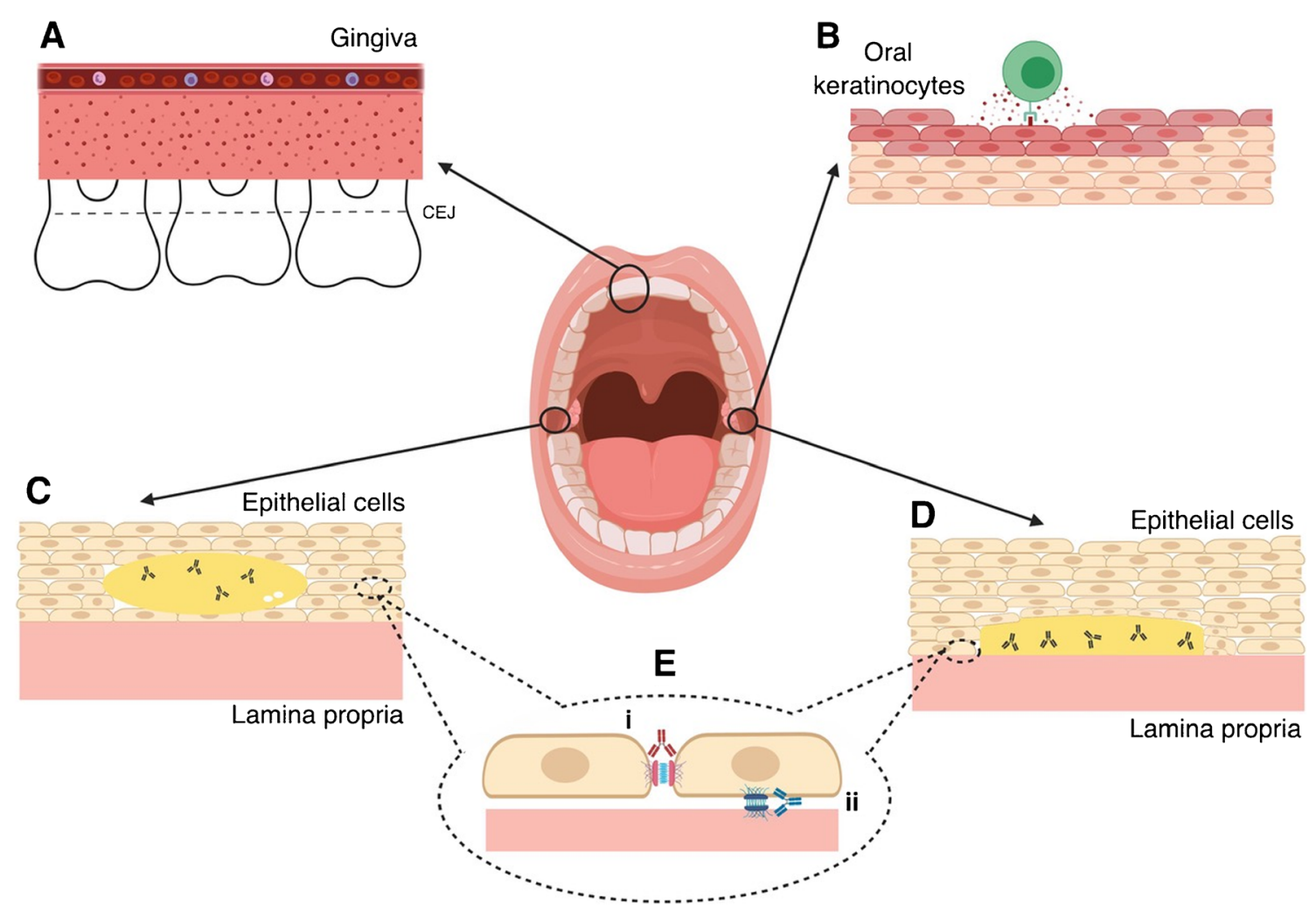

Fig. 2 The effects of autoimmune diseases in the oral cavity. In rheumatoid arthritis, there is a predisposition to periodontitis, and infection with periodontal disease associated bacteria has been proposed to contribute to pathogenesis of rheumatoid arthritis (A). In lichen planus, $\mathrm{CD} 8+\mathrm{T}$ lymphocytes predominate in oral lesions, characterised by inflammation, swelling, and damage to oral keratinocytes (B). In pemphigus, intra-epithelial blisters form due to self-recognising antibodies directed against desmosomes, which are crucial for cell-cell attachment $(\mathbf{C})$. Alternatively, in pemphigoid, antibodies become directed against hemidesmosomes, which function to anchor epithelial cells to the lamina propria. The result of this is the formation of large, fluid-filled blisters between the cells and lamina propria, which in severe cases may cause detachment (D). Detailed schematic of pemphigus i) (red antibody against desmosomes and pemphigoid ii) (blue antibody against hemidesmosomes $(\mathbf{E})$. Image created using BioRender

antigens against La/SSB/TRIM21 and Ro60/TROVE2. As such, these act as important diagnostic markers for SjS [26].

There have been multiple classification criteria for $\mathrm{SjS}$ previously. The most recent are those developed by American College of Rheumatology (ACR) and the European League Against Rheumatism (EULAR) in 2016 [26]. This classification allows for the simultaneous assessment of multiple systems that may be involved in $\mathrm{SjS}$. As such, it has proven to be effective at both reaching a diagnosis and monitoring disease progression. It has also been beneficial in randomised controlled trials; important due to the potential development of biologics and other agents that may be used in the treatment of $\mathrm{SjS}[27]$.

A recent systematic review showed that $60.82(95 \%$ CI 43.69 to 77.94 ) per 100,000 people suffer from $\mathrm{SjS}$, with a strong female predilection ratio of $10.72(95 \%$ CI 7.35 to 15.62), the mean age of patients with $\mathrm{SjS}$ was $56.16(95 \% \mathrm{CI}$ 52.54 to 59.78$)[28,29]$.

Currently, there is no cure for $\mathrm{SjS}$, as such management is centred around slowing disease development and symptomatic relief. Despite biologic agents being routinely used for other opment. The commonly cited auto-antibodies in $\mathrm{SjS}$ are 
ADs, they are not in routine use in SjS; however, work continues in this area [30].

Management from the dental team focuses on prevention and reducing oral discomfort. This includes regular oral examination, provision of high-fluoride toothpaste alongside other caries preventative methods. Saliva replacements often offer little benefit, as such conservative advice including drinking water regularly and using chewing gum may provide some relief for patients [31]. Patients with $\mathrm{SjS}$ are at an increased risk of developing B cell lymphoma, which may present as swelling local to the oral cavity and salivary glands, reinforcing the need for regular dental assessment and vigilance with regard to newly arising swellings [25].

\section{Diabetes}

Chronic hyperglycaemia of diabetes results in damage to the cardiovascular system, kidneys, eyes, nerves, and patients are often immunocompromised [32]. There are multiple oral implications of diabetes. This review focuses on type 1 diabetes due to its autoimmune pathophysiology [33]. Diabetes treatment focuses on regulating blood glucose levels through regular testing of levels, the use of insulin, and diet control.

Type 1 diabetes arises from the autoimmune destruction of insulin-secreting pancreatic $\beta$ cells causing decreased insulin production. Further to this long-standing disease often results in a total loss of insulin production. However, $10-30 \%$ of patients have no detectable auto-antibodies, and in these cases, the pathogenesis of diabetes remains unclear [34••].

Diabetes has conclusively been shown to be a risk factor for periodontal disease, and this relationship has been extensively studied and reviewed $[35,36]$. Elevated $\mathrm{HbA} 1 \mathrm{c}$ is associated with greater prevalence of disease and periodontal destruction, and glycaemic control appears to be the main predictor of attachment loss and subsequent tooth loss. Specifically, an $\mathrm{HbA1c}$ of greater than $7.0 \%$ appears to determine if a diabetic has and elevated PD risk [37•].

Periodontal disease negatively impacts glycaemic control and the development of nephropathy in diabetic patients [38, 39]. A recent systematic review of $\mathrm{HbA1c}$ levels following periodontal treatment concluded an average reduction of $0.46 \%$ of $\mathrm{HbA} 1 \mathrm{c}$ in diabetic patients who received periodontal treatment [40]. Thus, it is evident that there is a bidirectional relationship between PD and diabetes; the mechanisms of which are not fully understood but are thought to relate to the increased in pro-inflammatory mediators, which are involved in both diabetes and PD. [36]

These studies highlight the importance of ensuring that diabetes is well controlled in patients with periodontal disease, and that periodontal treatment can positively influence diabetic control.
Diabetes is a cause of xerostomia, as such, persistent drymouth should be investigated appropriately [41]. Further to this, the resulting immunocompromisation from chronic hyperglycaemia predisposes diabetics to fungal infections, delayed healing after surgery, and acute dental infection that may develop quicker and take longer to resolve [42]. Thus, it is imperative for diabetics to undergo regular dental assessment and have an appropriate prevention strategy implemented.

\section{Lupus}

The ADs discussed thus far do not directly impact the oral cavity, i.e., the auto-antigens are not directed against the oral cavity. However, Systemic Lupus Erythematous (SLE) represents an interesting challenge due to its heterogeneous clinical manifestations - one of which being oral mucosal lesions. Lupus is described as a rare disease with an incidence of 4.91/100,000 people over a 3-year period; however, although incidence appears to be declining, its prevalence appears to be rising to $97.04 / 100,000$ in 2012. Persons of Black Caribbean ethnicity have the highest incidence and prevalence [43]. There is a higher female predilection in SLE, with an affected female to male ratio of 10-15:1 [44].

Lupus is a chronic AD, which affects multiple body systems including the respiratory, dermatological, musculoskeletal, renal, and cardiovascular systems. Lupus goes through periods of remission and relapse, increasing the complexity of disease management. The varied presentation of lupus is likely due to auto-antibodies being produced against nuclear and cell membrane phospholipid components. The American College of Rheumatology use the presence of auto-antibodies for double-stranded DNA and antibodies against snRNP as lupus diagnositics [45]. These molecules are associated with apoptosis [46].

SLE auto-antibodies target the oral cavity directly, resulting in erythema and/or erosion with surrounding white striae, similar to that seen in oral lichen planus. Lupus lesions can affect any oral site. However, compared with lichen planus, lupus lesions more often present on the palate. Oral squamous cell carcinoma may arise within these sites, suggesting that it may be potentially malignant [47]. As with other ADs, treatment for SLE often results in immune compromise leading to an increased risk of fungal infection.

A recent study shows that SLE has negative effects on oral health that extend to compromise the quality of life. The exact mechanisms of this are unclear [48].

\section{Oral Lichen Planus}

Oral lichen planus (OLP) is a chronic inflammatory condition. Both antigen-specific and non-specific mechanisms play a 
role in its pathophysiology [49]. OLP manifests as a result of apoptosis of basal keratinocytes-induced by $\mathrm{CD} 8^{+} \mathrm{T}$ cells (Fig. 2B). This damage to the basal layer makes it easier for leukocytes to move into the intra-epithelial space and results in self-perpetuating inflammation [50]. In addition, there are more degranulated mast cells present in OLP tissue compared to normal oral mucosa; degranulated mast cells release proinflammatory mediators and upregulate endothelial cell adhesion molecules, shown to be important in OLP pathogenesis $[49,51,52]$. Clinically, this results in painful areas of erythema, erosions, and white patches. This primarily affects the tongue and buccal mucosa but may also present as desquamative gingivitis. OLP is potentially malignant, and transformation occurs in around 1\% of cases [53]. OLP prevalence is between 1 and $2 \%$ and has a female predilection [54, 55]. Lichen planus may also affect skin and genitals, these sites are implicated in 20 and $15 \%$ of OLP cases, respectively. OLP is seen in $70-77 \%$ of cutaneous lichen planus [56]. Whilst the exact cause of OLP remains elusive, genetic and environmental factors play a role in its pathogenesis [57•]. Environmental factors involved in OLP include trauma, dental materials, toothpastes, and systemic medications [56].

Oral Lichenoid Reactions (OLR) can be seen as either an exacerbation of OLP to an environmental factor or a separate disease entity, removal or modification of this factor will result in improvement or resolution of the lesions [56].

There is no cure for OLP as such management is focused on the symptomatic control of the disease. Treatment of the disease includes the modification of exacerbating factors, such as change of mediations implicated in OLP, removal and replacement of amalgam fillings, and modification of sharp dental cusps [58]. Topical agents used include benzydamine or steroid preparations [59]. In more severe cases, immunemodulating drugs such as tacrolimus, retinoids, dapsone, and mycophenolate may be necessary [51].

SLE has a similar clinical presentation to OLP, and graft versus host disease, which affects $40-70 \%$ of engrafted patients that may present with similar clinical and histologic features. Hence, differential diagnosis for suspected OLP lesions is important [60-62].

\section{Pemphigus}

The vesico-bullous disorder pemphigus is an $\mathrm{AD}$ with the clinical presentation of blisters which evolve to painful erosions that can affect both skin and mucous membranes [63]. Bullae formation occurs as a result of acantholysis caused by the destruction of desmosomes. Specifically, $\operatorname{IgG}$ autoantibodies are directed against desmoglein 3 and desmoglein 1 , resulting in loss of intra-epithelial keratinocyte adhesion [63] (Fig. 2C).
Oral presentation of pemphigus occurs in $50-90 \%$ of cases and is the first manifestation of the disease in around $18 \%$ of patients. Blisters and ulcerations can be present in any area of the oral mucosa, but most frequently those exposed to trauma [64].

Diagnosis of the disease is reached through clinical, histologic, and immunologic examination. Clinically, if pressure is applied often blisters will result, known as Nikolsky's sign, this may indicate the presence of a blistering condition; however, concerns are raised as to its specificity and sensitivity, as well as the adverse effect of inducing blisters [63]. The histologic examination should be undertaken, specifically, direct immunofluorescence will often identify a 'basket weave' appearance, showing the intra-epithelial location of auto-antibodies. Indirect immunofluorescence will detect circulating antibodies [63, 65].

Treatment of pemphigus is focused on providing symptomatic relief. Systemic corticosteroids, mycophenolate, and azathioprine are commonly used in the management of pemphigus. The biologic agent rituximab, a monoclonal anti-CD20 antibody, has been shown to achieve complete remission in $59-100 \%$ of cases; however, a relapse rate of $40-81 \%$ is reported [63].

\section{Pemphigoid}

Pemphigoid has a similar presentation to pemphigus, namely the formation of blisters, which often result in painful ulcers when burst $[66,67]$. It can affect the skin in addition to mucous membranes. This results in a sub-epidermal blister, these are more robust than those seen in pemphigus, and Nickolsky's sign is negative [64, 68].

The blisters result from IgG auto-antibodies directed against collagen XVII and dystonin-e; this in turn leads to destruction of hemidesmosomes responsible for the attachment of the epidermis and epithelium to basement membranes (Fig. 2D). The factors that induce pemphigoid are not understood. A genetic predisposition is important in its aetiology [69].

Clinical, histopathological, and immunofluorescence are employed in reaching a diagnosis of pemphigus. Histologic findings may show subepithelial bulla with some inflammation $[67,70]$. Direct immunofluorescence is the gold standard for diagnosis of pemphigoid. It will typically show IgG at the basement membrane in a linear appearance, allowing differentiation between it and pemphigus [71], [72] (Fig. 2E). Indirect immunofluorescence will show the presence of $\operatorname{IgG}$ antibodies [72].

Management of pemphigoid typically involves the use of systemic corticosteroids, and topical steroids may also be used in addition to or in isolation, if the affected area is small. Systemic treatment may include methotrexate and dapsone [67]. 


\section{Conclusion}

ADs can directly and indirectly affect the oral cavity and have a variety of clinical presentations. Whilst we still do not fully understand some of the mechanisms that cause ADs in the mouth or the mechanisms that cause systemic AD to impact the oral cavity, clearly, there is a bidirectional relationship. Maintaining good oral health is an important, yet often overlooked, component to the management of patients with ADs. Further studies will elucidate insights to the exact mechanisms that regulate $\mathrm{AD}$ in the oral cavity and the relationship between systemic $\mathrm{AD}$ and the oral cavity.

\section{Compliance with Ethical Standards}

Conflict of Interest The authors declare that they have no conflict of interest.

Human and Animal Rights and Informed Consent This article does not contain any studies with human or animal subjects performed by any of the authors.

Open Access This article is distributed under the terms of the Creative Commons Attribution 4.0 International License (http:// creativecommons.org/licenses/by/4.0/), which permits unrestricted use, distribution, and reproduction in any medium, provided you give appropriate credit to the original author(s) and the source, provide a link to the Creative Commons license, and indicate if changes were made.

Publisher's Note Springer Nature remains neutral with regard to jurisdictional claims in published maps and institutional affiliations.

\section{References}

Papers of particular interest, published recently, have been highlighted as:

- Of importance

•• Of major importance

1.• Julkunen A, Heikkinen AM, Söder B, Söder P-Ö, Toppila-Salmi S, Meurman JH. Autoimmune diseases and oral health: 30-year follow-up of a Swedish cohort. Dent J. 2017;6(1):E1. https://doi.org/ $10.3390 /$ dj6010001 A large study showing a relationship between autoimmune disease and oral health.

2. Anaya J-M, Ramirez-Santana C, Alzate MA, Molano-Gonzalez N, Rojas-Villarraga A. The autoimmune ecology. Front Immunol. 2016;7:139. https://doi.org/10.3389/fimmu.2016.00139.

3. Bolon B. Cellular and molecular mechanisms of autoimmune disease. Toxicol Pathol. 2012;40(2):216-29. https://doi.org/10.1177/ 0192623311428481.

4. Bluestone JA, Matthews J. The immune tolerance network: tolerance at the crossroads. Philos Trans R Soc Lond Ser B Biol Sci. 2001;356(1409):773-6. https://doi.org/10.1098/rstb.2001.0847.

5. Cusick MF, Libbey JE, Fujinami RS. Molecular mimicry as a mechanism of autoimmune disease. Clin Rev Allergy Immunol. 2012;42(1):102-11. https://doi.org/10.1007/s12016-011-8294-7.

6. Rojas M, Restrepo-Jiménez P, Monsalve DM, Pacheco Y, AcostaAmpudia Y, Ramírez-Santana C, et al. Molecular mimicry and autoimmunity. J Autoimmun. 2018;95:100-23. https://doi.org/10. 1016/j.jaut.2018.10.012.

7. Schmidt CW. Questions persist: environmental factors in autoimmune disease. Environ Health Perspect. 2011;119(6):A249-53. https://doi.org/10.1289/ehp.119-a248.

8. Ludwig RJ, Vanhoorelbeke K, Leypoldt F, Kaya Z, Bieber K, McLachlan SM, et al. Mechanisms of autoantibody-induced pathology. Front Immunol. 2017;8:603. https://doi.org/10.3389/ fimmu.2017.00603.

9. Allen A, Carville S, McKenna F. Guideline Development Group. Diagnosis and management of rheumatoid arthritis in adults: summary of updated NICE guidance. BMJ. 2018;362:k3015. https:// doi.org/10.1136/BMJ.K3015.

10. Brusca SB, Abramson SB, Scher JU. Microbiome and mucosal inflammation as extra-articular triggers for rheumatoid arthritis and autoimmunity. Curr Opin Rheumatol. 2014;26(1):101-7. https://doi.org/10.1097/BOR.0000000000000008.

11. Smolen JS, Aletaha D, McInnes IB. Rheumatoid arthritis. Lancet. 2016;388(10055):2023-38. https://doi.org/10.1016/S01406736(16)30173-8.

12. Van Gaalen FA, Van Aken J, Huizinga TWJ, et al. Association between HLA class II genes and autoantibodies to cyclic citrullinated peptides (CCPs) influences the severity of rheumatoid arthritis. Arthritis Rheum. 2004;50(7):2113-21. https://doi.org/10. 1002/art.20316.

13. Sabharwal UK, Vaughan JH, Fong S, Bennett PH, Carson DA, Curd JG. Activation of the classical pathway of complement by rheumatoid factors. Arthritis Rheum. 1982;25(2):161-7. https:// doi.org/10.1002/art.1780250208.

14.• Äyräväinen L, Leirisalo-Repo M, Kuuliala A, et al. Periodontitis in early and chronic rheumatoid arthritis: a prospective follow-up study in Finnish population. BMJ Open. 2017;7:e011916. https:// doi.org/10.1136/bmjopen-2016-011916 Accessed august 8, 2018. A study demonstarting that periodontitis is more prevelant in patients with rheumatoid arthritis.

15. Detert J, Pischon N, Burmester GR, Buttgereit F. The association between rheumatoid arthritis and periodontal disease. Arthritis Res Ther. 2010;12(5):218. https://doi.org/10.1186/ar3106.

16. How KY, Song KP, Chan KG. Porphyromonas gingivalis: an overview of periodontopathic pathogen below the gum line. Front Microbiol. 2016;7:53. https://doi.org/10.3389/fmicb.2016.00053.

17. Chukkapalli S, Rivera-Kweh M, Gehlot P, et al. Periodontal bacterial colonization in synovial tissues exacerbates collagen-induced arthritis in B10.RIII mice. Arthritis Res Ther. 2016;18(1):161. https://doi.org/10.1186/s13075-016-1056-4 A study showing that a key periodontal pathogen is associated with rheumatoid arthritis.

18. Kharlamova N, Jiang X, Sherina N, et al. Antibodies to Porphyromonas gingivalis indicate interaction between oral infection, smoking, and risk genes in rheumatoid arthritis etiology. Arthritis Rheumatol (Hoboken, NJ). 2016;68(3):604-13. https:// doi.org/10.1002/art.39491 A study showing that a key periodontal pathogen is associated with rheumatoid arthritis.

19. McInnes IB, Buckley CD, Isaacs JD. Cytokines in rheumatoid arthritis - shaping the immunological landscape. Nat Rev Rheumatol. 2016;12(1):63-8. https://doi.org/10.1038/nrrheum. 2015.171.

20. Yucel-Lindberg T, Båge T. Inflammatory mediators in the pathogenesis of periodontitis. Expert Rev Mol Med. 2013;15:e7. https:// doi.org/10.1017/erm.2013.8.

21. Mayer Y, Balbir-Gurman A, Machtei EE. Anti-tumor necrosis factor-alpha therapy and periodontal parameters in patients with rheumatoid arthritis. J Periodontol. 2009;80:1414-20. https://doi. org/10.1902/jop.2009.090015.

22. Kretapirom K, Okochi K, Nakamura S, Tetsumura A, Ohbayashi N, Yoshino N, et al. MRI characteristics of rheumatoid arthritis in the 
temporomandibular joint. Dentomaxillofac Radiol. 2013;42(4): 31627230. https://doi.org/10.1259/dmfr/31627230.

23. Liu F, Steinkeler A. Epidemiology, diagnosis, and treatment of temporomandibular disorders. Dent Clin N Am. 2013;57(3):465-79. https://doi.org/10.1016/J.CDEN.2013.04.006.

24. Kurtoglu C, Kurkcu M, Sertdemir Y, Ozbek S, Gürbüz C. Temporomandibular disorders in patients with rheumatoid arthritis: a clinical study. Niger J Clin Pract. 2016;19(6):715-20. https://doi. org/10.4103/1119-3077.164343.

25. Carr AJ, Ng W-F, Figueiredo F, Macleod RI, Greenwood M, Staines K. Sjögren's syndrome - an update for dental practitioners. Nat Publ Gr. 2012;213:353-7. https://doi.org/10.1038/sj.bdj.2012.890.

26. Psianou K, Panagoulias I, Papanastasiou AD, de Lastic AL, Rodi M, Spantidea PI, et al. Clinical and immunological parameters of Sjögren's syndrome. Autoimmun Rev. 2018;17:1053-64. https:// doi.org/10.1016/J.AUTREV.2018.05.005.

27. Seror R, Bowman SJ, Brito-Zeron P, Theander E, Bootsma H, Tzioufas A, et al. EULAR Sjogren's syndrome disease activity index (ESSDAI): a user guide. RMD Open. 2015;1(1):e000022. https://doi.org/10.1136/rmdopen-2014-000022.

28. Qin B, Wang J, Yang Z, Yang M, Ma N, Huang F, et al. Epidemiology of primary Sjögren's syndrome: a systematic review and meta-analysis. Ann Rheum Dis. 2015;74(11):1983-9. https:// doi.org/10.1136/annrheumdis-2014-205375.

29. Reksten TR, Jonsson MV. Sjögren's syndrome: an update on epidemiology and current insights on pathophysiology. Oral Maxillofac Surg Clin North Am. 2014;26(1):1-12. https://doi.org/ 10.1016/j.coms.2013.09.002.

30. Holdgate N, St Clair EW. Recent advances in primary Sjogren's syndrome. F1000Research. 2016;5:F1000. https://doi.org/10. 12688/f1000research.8352.1.

31. WHO | Diabetes programme. WHO. 2018. http://www.who.int/ diabetes/en/. Accessed September 4, 2018.

32. Acharjee S, Ghosh B, Al-Dhubiab BE, Nair AB. Understanding type 1 diabetes: etiology and models. Can J Diabetes. 2013;37(4): 269-76. https://doi.org/10.1016/J.JCJD.2013.05.001.

33. Atkinson MA, Eisenbarth GS, Michels AW. Type 1 diabetes. Lancet. 2014;383(9911):69-82. https://doi.org/10.1016/S01406736(13)60591-7.

34.• Liu Y, Bie R, Iwasaki LR, Nickel JC. Prevalence differentiations of periodontitis by diabetic status among US adults. J Diabetes. 2018;10(11):896-8. https://doi.org/10.1111/1753-0407.12781 A study showing increased prevelance in periodontal disease in patients with diabetes.

35. Shultis WA, Weil EJ, Looker HC, Curtis JM, Shlossman M, Genco $\mathrm{RJ}$, et al. Effect of periodontitis on overt nephropathy and end-stage renal disease in type 2 diabetes. Diabetes Care. 2007;30(2):306-11. https://doi.org/10.2337/dc06-1184.

36. Taylor GW, Burt BA, Becker MP, Genco RJ, Shlossman M, Knowler WC, et al. Severe periodontitis and risk for poor glycemic control in patients with non-insulin-dependent diabetes mellitus. J Periodontol. 1996;67(10s):1085-93. https://doi.org/10.1902/jop. 1996.67.10s.1085.

37. Faggion CM, Cullinan MP, Atieh M. An overview of systematic reviews on the effectiveness of periodontal treatment to improve glycaemic control. J Periodontal Res. 2016;51(6):716-25. https:// doi.org/10.1111/jre.12358 A review of systematic reviews showing that periodontal treatment does not improve glycameic control.

38. Mortazavi H, Baharvand M, Movahhedian A, Mohammadi M, Khodadoustan A. Xerostomia due to systemic disease: a review of 20 conditions and mechanisms. Ann Med Health Sci Res. 2014;4(4):503-10. https://doi.org/10.4103/2141-9248.139284.

39. Al-Maskari AY, Al-Maskari MY, Al-Sudairy S. Oral manifestations and complications of diabetes mellitus: a review. Sultan Qaboos
Univ Med J. 2011;11(2):179-86 http://www.ncbi.nlm.nih.gov/ pubmed/21969888. Accessed December 6, 2018.

40. Rees F, Doherty M, Grainge M, Davenport G, Lanyon P, Zhang W. The incidence and prevalence of systemic lupus erythematosus in the UK, 1999-2012. Ann Rheum Dis. 2016;75(1):136-41. https:// doi.org/10.1136/annrheumdis-2014-206334.

41. Preshaw PM, Alba AL, Herrera D, et al. Periodontitis and diabetes: a two-way relationship Matrix metalloproteinase NHANES National Health and Nutrition Examination Survey. Diabetologia. 2012;55:21-31. https://doi.org/10.1007/s00125-011-2342-y.

42. Demmer RT, Holtfreter B, Desvarieux M, Jacobs DR, Kerner W, Nauck M, et al. The influence of type 1 and type 2 diabetes on periodontal disease progression: prospective results from the Study of Health in Pomerania (SHIP). Diabetes Care. 2012;35(10):2036-42. https://doi.org/10.2337/dc11-2453.

43. Casciola-Rosen L, Andrade F, Ulanet D, Wong WB, Rosen A. Cleavage by granzyme B is strongly predictive of autoantigen status: implications for initiation of autoimmunity. J Exp Med. 1999;190(6):815-26 http://www.ncbi.nlm.nih.gov/pubmed/ 10499920. Accessed December 5, 2018.

44. Menzies S, O'Shea F, Galvin S, Wynne B. Oral manifestations of lupus. Irish J Med Sci (1971). 2018;187(1):91-3. https://doi.org/10. 1007/s11845-017-1622-z.

45. Rees F, Doherty M, Grainge MJ, Lanyon P, Zhang W. The worldwide incidence and prevalence of systemic lupus erythematosus: a systematic review of epidemiological studies. Rheumatology. 2017;56(11): 1945-61. https://doi.org/10.1093/rheumatology/kex260.

46. Riemekasten G, Hahn BH. Key autoantigens in SLE. Rheumatology. 2005;44(8):975-82. https://doi.org/10.1093/ rheumatology/keh688.

47. Corrêa JD, Branco LGA, Calderaro DC, Mendonça SMS, Travassos DV, Ferreira GA, et al. Impact of systemic lupus erythematosus on oral health-related quality of life. Lupus. 2018;27(2): 283-9. https://doi.org/10.1177/0961203317719147.

48. Sugerman PB, Savage NW, Walsh LJ, Zhao ZZ, Zhou XJ, Khan A, et al. The pathogenesis of oral lichen planus. Crit Rev Oral Biol Med. 2002;13(4):350-65 http://www.ncbi.nlm.nih.gov/pubmed/ 12191961.

49. Au J, Patel D, Campbell JH. Oral lichen planus. Oral Maxillofac Surg Clin North Am. 2013;25(1):93-100. https://doi.org/10.1016/j. coms.2012.11.007.

50. Lavanya N, Jayanthi P, Rao UK, Ranganathan K. Oral lichen planus: an update on pathogenesis and treatment. J Oral Maxillofac Pathol. 2011;15(2):127-32. https://doi.org/10.4103/ 0973-029X.84474.

51. Regezi JA, Dekker NP, MacPhail LA, Lozada-Nur F, McCalmont TH. Vascular adhesion molecules in oral lichen planus. Oral Surg Oral Med Oral Pathol Oral Radiol Endod. 1996;81(6):682-90. https://doi.org/10.1016/S1079-2104(96)80074-6.

52. Fitzpatrick SG, Hirsch SA, Gordon SC. The malignant transformation of oral lichen planus and oral lichenoid lesions. J Am Dent Assoc. 2014;145(1):45-56. https://doi.org/10.14219/jada.2013.10.

53. Eisen D, Carrozzo M, Bagan Sebastian J-V, Thongprasom K. Number V Oral lichen planus: clinical features and management. Oral Dis. 2005;11(6):338-49. https://doi.org/10.1111/j.1601-0825. 2005.01142.x.

54. Xue J-L, Fan M-W, Wang S-Z, Chen X-M, Li Y, Wang L. A clinical study of 674 patients with oral lichen planus in China. J Oral Pathol Med. 2005;34(8):467-72. https://doi.org/10.1111/j.1600-0714. 2005.00341.x

55. Alrashdan MS, Cirillo N, McCullough M. Oral lichen planus: a literature review and update. Arch Dermatol Res. 2016;308(8): 539-51. https://doi.org/10.1007/s00403-016-1667-2.

56. Bermejo-Fenoll A, López-Jornet P. Familial oral lichen planus: presentation of six families. Oral Surg Oral Med Oral Pathol Oral 
Radiol Endod. 2006;102(2):e12-5. https://doi.org/10.1016/j. tripleo.2006.03.016.

57. Gupta S, Ghosh S, Gupta S. Interventions for the management of oral lichen planus: a review of the conventional and novel therapies. Oral Dis. 2017;23(8):1029-42. https://doi.org/10.1111/odi.12634 A review of lichen planus therapeitics including novel therapies.

58. Patil A, Prasad S, Ashok L, Sujatha GP. Oral bullous lichen planus: case report and review of management. Contemp Clin Dent. 2012;3(3):344-8. https://doi.org/10.4103/0976-237X.103634.

59. Findler M, Garfunkel AA. Oral lichen planus as a clinical sign of graft-versus-host disease. N Engl J Med. 2003;349(23):2223. https://doi.org/10.1056/NEJMicm010397.

60. Sánchez AR, Sheridan PJ, Rogers RS. Successful treatment of oral lichen planus-like chronic graft-versus-host disease with topical tacrolimus: a case report. J Periodontol. 2004;75(4):613-9. https:// doi.org/10.1902/jop.2004.75.4.613.

61. Imanguli MM, Alevizos I, Brown R, Pavletic SZ, Atkinson JC. Oral graft-versus-host disease. Oral Dis. 2008;14(5):396-412. https://doi.org/10.1111/j.1601-0825.2008.01448.x.

62. Kasperkiewicz M, Ellebrecht CT, Takahashi H, Yamagami J, Zillikens D, Payne AS, et al. Pemphigus. Nat Rev Dis Prim. 2017;3:17026. https://doi.org/10.1038/nrdp.2017.26.

63. Martinez AB, Corcuera MM, Ilundain CB, Gómez GE. Oral manifestations of pemphigus vulgaris: clinical presentation, differential diagnosis and management. J Clin Exp Dermatol. 2010;01(02):1-4. https://doi.org/10.4172/2155-9554.1000112.

64. Cholera M, Chainani-Wu N. Management of pemphigus vulgaris. Adv Ther. 2016;33(6):910-58. https://doi.org/10.1007/s12325016-0343-4.

65. Dharman S, Muthukrishnan A. Oral mucous membrane pemphigoid - two case reports with varied clinical presentation. J Indian
Soc Periodontol. 2016;20(6):630-4. https://doi.org/10.4103/jisp. jisp_155_16.

66. Bağc1 IS, Horváth ON, Ruzicka T, Sárdy M. Bullous pemphigoid. Autoimmun Rev. 2017;16(5):445-55. https://doi.org/10.1016/j. autrev.2017.03.010.

67. Soni A. Nikolsky's sign - a clinical method to evaluate damage at epidermal-dermal junction. J Indian Acad Oral Med Radiol. 2018;30(1):68. https://doi.org/10.4103/jiaomr.jiaomr 9517.

68. Delgado JC, Turbay D, Yunis EJ, Yunis JJ, Morton ED, Bhol K, et al. A common major histocompatibility complex class II allele HLA-DQB1* 0301 is present in clinical variants of pemphigoid. Proc Natl Acad Sci U S A. 1996;93(16):8569-71 http://www.ncbi. nlm.nih.gov/pubmed/8710911. Accessed December 6, 2018.

69. Machado-Pinto J, McCalmont TH, Golitz LE. Eosinophilic and neutrophilic spongiosis: clues to the diagnosis of immunobullous diseases and other inflammatory disorders. Semin Cutan Med Surg. 1996;15(4):308-16. https://doi.org/10.1016/S1085-5629(96) 80044-7.

70. Vodegel RM, Jonkman MF, Pas HH, De Jong MCJM. U-serrated immunodeposition pattern differentiates type VII collagen targeting bullous diseases from other subepidermal bullous autoimmune diseases. Br J Dermatol. 2004;151(1):112-8. https://doi.org/10.1111/j. 1365-2133.2004.06006.x.

71. Sárdy M, Kostaki D, Varga R, Peris K, Ruzicka T. Comparative study of direct and indirect immunofluorescence and of bullous pemphigoid 180 and 230 enzyme-linked immunosorbent assays for diagnosis of bullous pemphigoid. J Am Acad Dermatol. 2013;69(5):748-53. https://doi.org/10.1016/j.jaad.2013.07.009.

72. González S, Sung H, Sepúlveda D, González M, Molina C. Oral manifestations and their treatment in Sjögren's syndrome. Oral Dis. 2014;20(2):153-61. https://doi.org/10.1111/odi.12105. 